\title{
Case Study Research on Strategic Management of Alpha Company
}

\author{
Heming Feng \\ Department of Business Administration, South China University of Technology, Guangzhou, China \\ Email: fengheminghld@163.com
}

How to cite this paper: Feng, H.M. (2018) Case Study Research on Strategic Management of Alpha Company. Journal of Human Resource and Sustainability Studies, 6, 61-80.

https://doi.org/10.4236/jhrss.2018.61027

Received: February 28, 2018

Accepted: March 20, 2018

Published: March 23, 2018

Copyright $\odot 2018$ by author and Scientific Research Publishing Inc. This work is licensed under the Creative Commons Attribution International License (CC BY 4.0).

http://creativecommons.org/licenses/by/4.0/

\begin{abstract}
Alpha is a diversified listed company, which developed from a single toy company to a company with four business sectors. Its development strategy is worth being studied. This essay focuses on Alpha's corporate-level strategies. With the introduction and analysis of the internal and external environment of Alpha Company, and combining with the analysis of the company business model, the paper used the analysis tools such as SWOT and PEST to study the management model and business portfolios of the company. In the process of diversification development of many Chinese enterprises, they often focus on business-level strategy, while ignoring the importance of corporate-level strategy. This may make them ignore the expansion of investment, support of the core business and the coordination of the business. Therefore, the corporate strategy is an important factor for the enterprise's development. Then, the paper draws the conclusion that the management model needed to be adjusted, and the business portfolios needed to be improved. According to this conclusion, it figured out the Alpha's strategic objectives and planning schemes, and set the diversification strategy, which might be suitable for the company development. Finally, the paper put forward the concrete measures of corporate-level strategy, including five aspects of the management adjustment measures, which are the adjustment of the organizational structure, the management of the integration of acquisition resources, $R \& D$ resources' integration, integration of human resources and integration of sales resources. Conclusions might provide some effective suggestions for building the company's long-term strategy.
\end{abstract}

\section{Keywords}

Alpha, The Whole Chain Strategy, Diversification 


\section{Introduction}

Animation industry is one of the most potential industries in twenty-first Century. Japan's animation industry ranked first in the world, accounting for more than seventy percent share of the global animation. In 2012, the global animation industry's output reached 222,800 million dollars, and animation related derivative products' output value of more than $\$ 500,000,000,000$ [1]. The animation industry has become a huge industry in the recent world.

China animation industry in China is an emerging industry and has developed fast in the recent year. But it still has a large gap, comparing with that in America or Japan. China's animation industry is still in its early stages of development, and will benefit more from the transformation and upgrading of the quality and efficiency brought with improvement. We have seen China's animation industry output reached 100 billion yuan in 2014. Although the Chinese animation industry maintains sustained growth, China's animation industry is still in a bad position comparing with that in Japan and the United States [2]. Japan's animation industry output value is 230 trillion yen every year (about 18 trillion yuan). It had become the second largest pillar industry in Japan. We can see that China's animation industry size and influence are still weak.

In 2012, the Ministry of Culture officially released the "Twelfth Five Year Plan" period of national animation industry development planning, which is the first time for single planning of animation industry in China [3]. During the "Twelfth Five Year Plan", our country will focus on creating several well-known domestic cartoon brands and famous animation companies, and will encourage all kinds of capital investment in the animation industry. The twelfth-five year plan guides the animation creation, production, "innovative profit model, improving the animation industry chain", optimizing the layout and structure of the animation industry, animation technology innovation, promoting the implementation of enterprises, talents, promoting the animation industry go to the seven aspects of the start. China has made specific requirements for the implementation of the target, the development from big country that watches the animation to powerful animation industry that makes the animation.

Compared with the animation industry, toy industry outlook is slightly inferior. China is one of the largest toy producers in the world and is also one of the largest exporter of toys, $75 \%$ of the world's toy manufacturing in China [3]. However, most of the toys are original equipment manufacture-based. The number of Chinese self-developed toys is less than $1 / 3$ comparing with the total. This template, created in MS Word 2007, provides authors with most of the formatting specifications needed for preparing electronic versions of their papers. All standard paper components have been specified for three reasons: ease of use when formatting individual papers; automatic compliance to electronic requirements that facilitate the concurrent or later production of electronic products; conformity of style throughout a journal paper. Margins, column widths, line spacing, and type styles are built-in; examples of the type styles are 
provided throughout this document and are identified in italic type, within parentheses, following the example. Some components, such as multi-leveled equations, graphics, and tables are not prescribed, although the various table text styles are provided. The formatter will need to create these components, incorporating the applicable criteria that follow.

\section{Literature Review}

\subsection{Strategy's Origin}

The word strategy's the earliest concept is from the military. In the west, "strategy" comes from the Greek "Strategos", meaning the military general. Western strategy first appeared in the sixth Century, in 579. East Rome (Byzantine) Empire emperor Maurice wrote a book for training the senior general, named "strategicon", meaning "to the general". The "strategy" comes from "strategicon". In China, "strategy" has a long history, "zhan" refers to the war, "lv" refers to the strategy. During the spring and Autumn period, Sun Wu's "art of war" is considered to be the earliest Chinese of strategic planning [4].

France Romini definition of strategy in the "Introduction the art of war" is the strategy is to invade another country or to defend its command army on the battlefield is an army troops to the war zone or area of operations decided on art. Germany Clausewitz wrote in "on war", the most important strategic [5]. Canadian Henry Mintzberg believed that at least 5 kinds of definition of strategy: strategy is a plan, guide to the future; strategy is a kind of pattern, the consistency of long-term operation; strategy is a kind of position, strategy is a kind of perspective, that is the basic way of doing things, an organization's corporate philosophy; strategy is the ploy, namely the specific strategy to defeat opponents or rivals.

\subsection{Enterprise Strategy Levels}

Corporate strategy is made by the headquarters that have industry diversification and market diversification. The main objective is to maximize profitability. No matter the relationship and the management of the unit is the mother child relationship or headquarters division relationship, it is mainly to achieve rationalization investment returns through the industry or market diversification [6]. Therefore, the core content of corporate level strategy is a multi industry and multi market portfolio.

Business strategy is a single industry or a single market business strategy, whether the single industry or a single business unit is an independent legal person or not. Its main purpose is to maximize market share and profit. Business-level strategy is to achieve maximum profit [7], through product, service business, competition and market share. Its core content including the target market and customer choice, management orientation and mode choice, and the creation and management mode.

Functional level strategy is to develop functional strategy by the departments 
in the enterprise. There are various levels within the enterprise management and operation of functional departments, they are neither investment center, profit center, but the cost or cost center. In order to achieve the company or the business level strategy, these functions, according to the requirements of the two level requirements, formulate the corresponding function strategy [8]. The template is used to format your paper and style the text. All margins, column widths, line spaces, and text fonts are prescribed; please do not alter them. You may note peculiarities. For example, the head margin in this template measures proportionately more than is customary. This measurement and others are deliberate, using specifications that anticipate your paper as one part of the entire journals, and not as an independent document. Please do not revise any of the current designations.

\subsection{The Whole Industry Chain}

\subsubsection{Origins}

The whole industry chain is proposed by COFCO, a model of development in the Chinese household food consumption, upgrading agricultural industry. The strategy is similar to the monopoly in order to compete in today's market to grab market share.

\subsubsection{The Concept}

The whole industry chain is one of the business model that can embody the cultural industry best, which has "a meaning multi-use" feature. It presents the structure of cultural and creative resources in the same space and time dimension, showing a greater coherence and Extensibility. Formation and improvement of the whole industry chain need to have abundant of human resources, a common unified core business philosophy of the whole industry chain, the vast physical space, and other support leading enterprises driving conditions. Through the whole industry chain, we can achieve vertical transverse chain extension and maximize the value of intangible assets in the international markets.

\subsubsection{The Whole Animation Industry Chain}

Animation industry chain can be simply divided into the upper creative production, midstream published play and downstream derivative development. In 2009, China surpassed Japan became the first television animation production in the world [9]. In 2012, China's animation industry output value reached 76 billion yuan, while the value of the United States in 2004 was \$ 250 billion anime, Japanese animation production value was $\$ 120$ billion in 2010 . The total output value of China's animation output value is less than the Disney animation one third in 2012. The main cause of low production and high value of China's animation industry are: lack of animation creative ability, weak profitability animation, animation piracy is serious and the animation industry chain imperfect's broke status [10]. 


\section{External Environment Analysis of Alpha}

For a more thorough study of Alpha company's strategy, it is necessary to make an objective analysis for Alpha's external environment. The purpose of analysis is to have a better understanding and grasp of the external environment and changes. It also can help the Alpha make an expansion. Here is the analysis of Alpha Company's macroeconomic environment using PEST method.

\subsection{Analysis of Chinese Macro Environment}

PEST is focus on the social macro environment analysis (Society), technology (Technology), (Economy), the economic and political/legal (Politics) five, because these factors are affecting the industry and the competitiveness of enterprises. These factors are often considered beyond the direct impact of individual enterprise category [11].

\subsubsection{The Political Environment Analysis}

The toy industry's political environment will drive the related consumer demand, because of the national "two separate child policy". From 2002 to 2004, the government has promulgated the "animation industry fifteen period development plan", "several opinions about the development of China's animation industry" and other related documents. The file pointed out that the Chinese animation ratio shall not be less than $70 \%$ and import animation shall not exceed the proportion of $30 \%$, to actively support domestic animation, gradually formed with national characteristics, suitable for the characteristics of minors. It shows the tradition of the Chinese cartoons. In 2005 May, SARFT issued a "specific measures on promoting the development of China's animation creation". In order to support domestic animation, the government encouraged all levels of television broadcast time, by adding time of animation column and also encouraging creating outstanding domestic cartoons. And when the right time came, the television must broadcast homemade cartoon in the primetime (17:00 to 21:00).

China first proposed to develop cultural and creative industries, high value-added in the animation industry in the "eleven five" plan. According to incomplete statistics, there are twenty provinces supporting the animation industry as an emerging industry, Beijing, Shanghai, Suzhou, Guangzhou, Shenzhen, Dalian and other places have introduced preferential policies; more than 200 colleges have set up the animation major.

SARFT issued a document that TV broadcast at least 30 minutes of domestic animation or TV program every day. Further analysis, once the 30 national TV station broadcast animation, then, high-quality animation will become a scarce resource. Perhaps, it is not the TV rights, but domestic animation will have a soaring price in the future [12].

\subsubsection{The Analysis of Economic Environment}

In 2009, CCTV Animation, Beijing brilliant animation and other 100 companies 
became the first to be found in the animation business. They will truly benefit from the value-added tax, corporate income tax, sales tax, import duties and import VAT five taxes.

At the Seventh China International Animation Fair, Shanghai released the latest animation and game industry support plan that annual investment of 10 million yuan reward fund to support the development of original animation production in June 24, 2011.

Guangdong Animation City is the focus by state and government to support development projects. The total planning area is about 2500 acres, planning to use three to five years to complete in three phases, with a total investment of 60 billion yuan. Guangdong Animation City animation focuses on building the animation industry chain integration platform business, through the introduction of large international groups, the introduction of international advanced technology to support domestic original animation development, foster domestic original animation and production personnel [5].

\subsubsection{The Analysis of Social Environment}

Teenagers are still the main consumers in China. According to "Friends of Man" magazine, we can see nearly eight years of investigation and analysis of the readership age groups constituting domestic cartoon readers as follows: under 13 years accounted for about $12 \%$ of population, $14-17$ years old accounted for $60 \%$, while the percent of more than 18 years is $30 \%$. While China has 367 million minors, the market is huge. Of course, in addition there are a number of adults [12].

Core animation industry is "creative." Chinese culture is one of the best cultures in the world, which has rich cultural resources, such as a large number of literary classics and famous people, a lot of poetry, classical and modern music, excellent tradition and culture, rich in cultural and natural tourism resources, the Chinese martial arts, traditional customs, traditional arts, etc. Our culture offers the endless creative material for the development of creative industries. Second, China's per capita disposable income increased year by year, the same as the spending power.

\subsubsection{The Analysis of Technical Environment}

Technically, the Chinese cartoon animation has the advantage in style by the influence of that in Japan and the US.

\subsection{Analysis of the Animation and Toy Industry Competitive Environment}

Every enterprise is in the corresponding industry. Before implementing the strategies, enterprises must thoroughly analyze their environment to grasp the key factors in the shortest time, to accurately predict trends of the external environment changes and make early response and timely adjustments to keep business making profits ability. External environmental factors not only affect the 
competitive behavior of enterprises, but also determine the profitability of the industry. Porter developed his Five Forces analysis in reaction to the then-popular SWOT analysis. It has been applied to a diverse range of problems, because helping businesses becomes more profitable to helping governments stabilize industries. Porter's five forces are as follows.

\subsubsection{Threat of New Entrants}

Toy market has low barriers to entry. There are many toy manufacturers in Guangdong. And the markets are more fragmented. As for animation market, too much pressure comes from the foreign animation companies and fierce competition among domestic companies. China as the world's largest producer, animation market has a large scale, especially in Guangdong, Shanghai, Zhejiang, Jiangsu and other places. The animation industry is almost saturated. New firms that want to enter the industry should have a certain number of requirements. The companies with too small input will be selected by the competition.

Animation industry in every industry must deal with the more or less threat, which a potential competitor is a potential entrant for the existing animation companies. For the presence of potential entrants, existing animation enterprises will make a corresponding payable action.

First, make technical barriers. The first step is to improve the brand image, by advanced equipment investment, technology updates, talent attraction, the establishment of high-precision end of the creative team, with their incumbent advantages.

Second, funding barriers. The cost of new entrants to enter is relatively high, because of the increase investment, high industry barriers, high salaries of creative teams. There is also a long recovery period to get money back. We can see that it is going to need tens of millions of funds to enter the animation industry. The major obstacle of entrants is the functions on the economies of scale of production, research and development, marketing, etc.

The offer price of animation products currently is very low, the making cost of one minute is 8000 - 10,000 yuan and an issue price is only a few hundred yuan a minute. So the customer does not offer attractive, its cost recovery depends mainly on the development of derivative products. Animation business is a cultural industry, actively encouraged by China's 12th Five-Year Plan. Developing and supporting the cultural industry has a lot of preferential policies, with no regulatory constraints. So fierce competition in the industry, but the advantages of leading enterprises already laid, the potential threat of new entrants is not great.

\subsubsection{The Bargaining Power of Suppliers}

Animation film and television works' upstream suppliers are good script, good theme, fine script requires a higher price, the strong bargaining power of suppliers. Animations rely on computer equipment and software to create. With the rapid development of high-tech industries, the market is full of software, com- 
puter equipment. So software suppliers' bargaining power is not strong.

\subsubsection{The Bargaining Power of Buyers}

Animations are mainly related to the purchase of copyright issues. Television has the right to choose, so the animation company is at a disadvantage. But if the company has the right to operate the cartoon TV, it will account for an advantage in the competition.

Toys major productions are original equipment manufacturer (OEM) enterprises or have their own brands. OEM enterprises' profit is lower, because they don't have initiative. If the enterprises have their own brands, toy sales will be greater.

Cartoon usually is bought by the media. A large number of outstanding domestic animation are needed from the central station to the other emerging media on provincial satellite station and the local stations, as well as networks. As the broadcast television market will try to choose better animation programs to broadcast. While the number of outstanding domestic animation production is too small, the demand exceeds the supply. Therefore, the media conversion capability is strong. There is no conversion fee. We felt that with the good brand effect and audience appeal of the work can have a bargaining power. In a word, the high quality animation will increase the bargaining power [13].

\subsubsection{The Threat of Substitutes}

The threat of substitutes is mainly from the following several aspects. First, animation from Europe and Japan has a stable customer base. Second, the domestic animation and toy companies that have a good development trend, especially the enterprises owing both animation and toys brands.

In recent years, the top 10 ranking of global toy sales company such as Japan Bandai, Hasbro United States, Denmark Lego has entered the Chinese market by adopting sales agent. Foreign investment has increased year by year. This makes foreign toy brands more than $30 \%$ increase of the rate, and sell directly from the factory in China to the Chinese market. The sales of Chinese toy market also increased with the rapid growth period.

Meanwhile, the international toy enterprises have its powerful ability to accelerate the development rate. They rely on the integration of development capabilities, talent accumulation, strong financial strength, channel operation capacity, brand communication. Along with the expansion of China toy market, the foreign animation enterprises expand children's mainstream consumer groups, at the same time actively cultivating young consumer groups, and monopolize the high-end toy market.

It is difficult for animation film and television product consumption experience to have alternatives. Animations as ornamental and experience-based cultural products, consumer experience is different from the books, opera and musicals, and other forms of cultural products. Colorful modern society drive people seeking self-identity, calling attention to the mind, concerning about the fate of ordinary people, and these are precisely the strengths of anime lies. Ac- 
tually, intuitive alternatives may be the pirated discs. But with copyright environment gradually optimized, high-definition playback support, modern digital cinema and IMAX technology gaining popularity, it will be difficult for animations to find alternatives.

\subsubsection{The Threat of Established Rivals}

The core competition is the competition among the market share. We know that the domestic animation companies can't compete with foreign companies, so the main competition is among domestic companies. Chinese cartoon toy market has great potential. Currently many successful animation companies have adopted "anime + toy" business model, which have a good development.

First, the export market is too concentrated and has the potential risks. China's toy industry is an export-oriented industry, and exports to a single market, mainly in the United States, the European Union and Japan. While the export market is too concentrated, it will increase the reducing risk of export, while China's toy industry faces the international economic situation decline and the major exporting countries make trade barriers.

Second, the increase in export cost and the decrease in profit. In recent years, a series of international and domestic factors lead to the increase of China's toy export costs, including: 1) RMB appreciation; 2) the United States and Europe and other major toy export market promoted China's toy export threshold, resulting in the increase of China's toy quality and safety supervision and equipment transformation investment; 3) The international oil prices continued to rise since 2004, plastic and other raw materials prices rose sharply; 4) China's labor force have moved from the toy industry to other industries which have pay better wages, resulting that labor wage must be improved. Superposition of these factors caused the production of China's toy industry is the sharp rise.

On the other hand, China's toy industry with OEM manufacturing-based is too concentrated. As for the bargaining, China's toy enterprises in a weak position comparing with foreign toy companies. In terms of causing foreign toy commission processing companies face rising costs of Toys when there is no corresponding increase in the purchase price. These two reasons lead to a substantial reduction in China's toy industry profits, some smaller, weak product development capabilities, the ability to deal with barriers to foreign toy companies is not strong, because the falls short of international standards, the profit space is too small, and can only be excluded international market outside.

Third, the domestic toy market showed great potential. Over reliance on foreign trade order, domestic too little is the problem of long-term development of China toy industry. In the face of toy exports, the development of the domestic market can make up for deficiency, which China has a potential and huge toy consumption market [14].

\subsubsection{Analysis of External Opportunities}

First, the Chinese cartoon toy market has reached a certain size, starting in 2011. Five years has maintained steady growth. Because animation is part of the toy 
market in the derivatives market of animation segments. Abroad, such as toys and animation combine marketing has been very mature, there will usually have related toy sale before the film on. For example, the United States, Australia and the United Kingdom and some other countries, the proportion of animation toys in the toy market is about $25 \%$.

With the rapid development of the animation industry, China's cartoon toys gradually rise, which have a quick development. Under the current government support, China's animation industry has good prospects for development, and derives huge cartoon toy market. It is lack of the companies that can integrate both toy and cartoon animation industry.

\subsection{Summary}

This chapter mainly uses the macro environment analysis theory and the porter five forces theory. We can learn that toy industry is totally different from animation industry. From the PEST analysis, the animation industry in China has a big room to develop. The toy industry is going down and it needs the support from the animation.

\section{Alpha's Strategy Analysis}

A company's strategy has a great impact for long-term development of the company. Therefore, a viable strategy determines the direction of long-term development of the company. Next, it is necessary for Alpha to make a formulation and implementation of strategic actions.

2014, overall penetration of the Internet economy, culture and consumer era begins in earnest. Including animation, literature, games, movies accelerate cross-border facility, a "pan-entertainment" ecological chain. IP-entertainment industry as the core of the pan into the mainstream culture formats, provides users with a multi-level, cross-media, cross-platform entertainment experience, depth, better market infrastructure and higher industrial value [15].

\subsection{Alpha’s Corporate Vision}

2014, overall penetration of the Internet economy, culture and consumer era begins in earnest. It has become a "pan-entertainment" ecological chain, including animation, literature, games; movies accelerate cross-border facility. Intellectual Property industry has became the mainstream culture, as the core of the pan, provides users with a multi-level, cross-media, cross-platform entertainment experience, depth, better market infrastructure and higher industrial value.

Alpha's vision is to become a world-class animation culture industry groups. The company will first upgrade the service industry and the development of animation content, and then use the profits to feed industry and promote the cause of animation and cartoon derivative undertaken to achieve industrial integration, to achieve mutual growth and industrial development of cultural undertakings, and ultimately from industrial culture to culture industrial upgrade. 
Alpha, its ultimate goal is to achieve animation content-driven industry.

\subsection{Strategic Orientation and Planning}

\subsubsection{The Overall Strategic Positioning of Alpha}

Prior to the development of corporate-level strategic goals, we need to position the company's overall strategic first. This chapter will use SWOT model analysis tool, through a combination of analysis of the results of the foregoing within the Alpha of the external environment, the company itself the strengths, weaknesses and Future Development Opportunity, threat on Alpha's elaborate analysis of the overall situation were to arrive at the overall strategic direction of the company's positioning.

The Strength "S" and weaknesses "W" are internal factors, opportunities "O" and threats " $\mathrm{T}$ " are external factors. With the front of the company's internal capabilities through analysis and resource analysis, combined with the second chapter of the external environment factors, the overall structure of the Alpha SWOT matrix model, more intuitive analysis Alpha's competitive advantage and where short board, and on this basis on selecting the appropriate strategy. Alpha's internal and external environment SWOT analysis is as follows.

S-Strength

1) Comparing to the international animation, Alpha's toy has cost-effective. Comparing to domestic animation companies, Alpha's toy has competitive advantage.

2) The acquisitions increased rapidly the market share and development capabilities of Alpha.

3) Alpha, domestic listed company, has a strong refinancing base.

4) Alpha's brand recognition is high, with good sales channels and customer resources base.

5) With the improvement of the organization, management and operation mechanism is relatively efficient, nurturing an experienced management and technical team.

6) Alpha has a good manufacturing ability. Use a zero before decimal points: “ 0.25 ”, not “. 25 ”. Use " $\mathrm{cm}^{3 ",}$ not "cc".

\section{O-Opportunity}

1) Toy industry is in a great opportunity for development. Because the national "single second child" policy-related startup drive consumer demand.

2) The "Eleventh Five-Year Plan" was first proposed to develop cultural and creative industries, high value-added industries such as the animation. According to incomplete statistics, there are more than two dozen cities across the country's animation industry as an emerging industry will strongly support.
W-Weakness

1) Alpha is one of the leaders at present. But the future will gradually fall behind, if it is unable to innovate.

2) Animation research and development technology foundation is weak.

3) Less cash flow and net asset share, Alpha still need to improve the anti-risk ability.

4) The synergy of the whole industry chain resources should be improved.

5) The core business of R \& D investment and technology should be improved.

6) Limited sales channels, and less electricity suppliers combined market coverage is not high.

\section{T-Threat}

1) Animation from Europe, America and Japan, have a glorious development history and a mature development, and they have a stable customer base.

2) In recent years, the top 10 ranking of global toy sales companies, such as Japan Bandai, Hasbro United States, Denmark has adopted higher music sales agent or establishment of foreign toy companies to enter the Chinese market, China Market, and to invest in China's toy production. 
3) SARFT issued the latest, from January 1 , 2014, every TV broadcast at least 30 minutes per day of domestic animation or children's programs. Further analysis, once the country's $30 \mathrm{TV}$ stations were to broadcast animation, then the quality of animation will become a scarce resource.

4) Alpha is the focus of state and government to support development projects. Guangdong Animation City animation business through the introduction of large international groups, the introduction of international advanced technology to support domestic original animation development, foster domestic original animation and production personnel, to build the animation industry chain integration platform.

5) The state has increased business innovation and industrial upgrading activity subsidies, effectively reducing the enterprises to upgrade to high-end industrial development costs and risks.
3) Teenager in China can say a few well-known homemade brands, more discussion is still Disney, Hasbro, Bandai, Mattel and other such international big companies.

4) China's toy industry are export-oriented industries and export markets single, mainly in the US, EU and Japan. The export market is too concentrated will make China's toy industry in the face of the international economic situation and falling trade barriers in major exporting countries, exports suffered a significant reduction in risk.

5) The increase the cost of exports further reduces the profits. In recent years, a series of international and domestic factors have led to increased cost of China's exports of toys, including: a) revaluation; b) the United States and Europe and other major toy export market continues to raise the threshold for China's toy exports, resulting in China's toy enterprises in product quality and safety control and a significant increase in investment in equipment modification.

From the factors listed above in-depth analysis, Alpha's existing biggest advantage is "has become the international advanced and development of the industrial base", the main disadvantage is the "toy Although the animation is currently living in the domestic leading level, lack of innovation and $\mathrm{R} \& \mathrm{D}$ reserves, there is the risk of being overtaken backward"; facing the biggest growth opportunities are "domestic toy market demand with national policy support for the development animation toy industry a good opportunity"; main threat is "the development of the history of animation from Europe and Japan, more glorious, the development of a more mature, has a stable customer base".

Though a comprehensive analysis of four factors and are paired together, we can draw the portfolio strategy as follows:

SO (Strength-opportunity) Growth Strategy: With the rapid development of market opportunities cartoon toys, the use of a leading competitive advantage in the expansion of business scale at the same time, looking for new economic growth point, timely cut upstream and downstream industry chain integration M \& A value in the development of some enterprises to enter new markets, vertical integration horizontal integration or expansion.

WT (weaknesses-threats) defensive strategy: stick to the current two core business of animation and toys, do not rush to expand development or large business transformation, innovation and R \& D by improving the level of market differentiation, cost reduction strategies to overcome their own weaknesses to enhance the competitive advantages of the business, in a more secure way to achieve its strategic goals, and to avoid external risks.

ST (Advantage-threats) diversification strategy: R \& D, product quality, cost, etc. to reduce the impact of external factors by leveraging Alpha's own advan- 
tages. You can also use the whole industry strategy, timely cut development potential of derivatives to avoid and mitigate competitive threats primary market in which the industry faces.

WO (weaknesses-opportunities) contractionary strategy: Reducing the company at a competitive disadvantage in industries will focus on the development of resources to carry out the toys and animation and other advantages of the core business, enabling the company to promptly seize external growth opportunities, by changing the business Disadvantages business combination or exit the market to solve development problems arising from short board.

According to Alpha Company's current performance, Alpha has continued the steady development of style, combining with the current economic slowdown. According to the direction of the overall strategy, Alpha should choose ST, a more diversification strategy, and strive to maintain the current rapid development trend of animation and toy two core industries, through strategic acquisitions to enter other related industries, by raising the level of research and development, market differentiation, cost reduction strategies to overcome their own weaknesses and enhance the core business strengths competitive. There is a diversified way to achieve strategic goals, to maintain the current market share advantage and to avoid the risk of the external environment.

\subsubsection{Alpha Strategic Objective}

Combining with the previous positioning of Alpha's overall strategy, Alpha's strategic development goals will be divided into the overall strategic objectives and each industrial unit strategic objectives.

\section{1) The overall strategic positioning of Alpha}

Alpha plans to have adjustment, innovation and R \& D capabilities of enterprises significantly increased, a substantial increase in the number of high quality innovative animation, through five-year development. Product structure to achieve significant upgrade optimization, animation innovation ability has been greatly improved, the company's animation product sales revenue's contribution rate will be more than $50 \%$. Driven by gains in animation toy products, the company's sales volume and profitability increased substantially, to achieve total revenue within three years more than 4 billion yuan, to achieve within five years total sales income over $\$ 6$ billion.

\section{Each industrial unit strategic objectives}

\section{a) Toy business}

To maintain the domestic market leading position through product innovation and marketing perspective, cartoon toys to maintain rapid growth. To further improve the sales of cartoon toys, Alpha should give toy a story and formulate marketing strategies. Make sure the market share is large enough to compete with the foreign toy companies.

b) Animation industry

Innovation capacity should be significantly improved. Learning from the recent "bear haunted", Alpha should be able to create a well-known animation in 2 
to 3 years. Through their own R \& D department, Alpha should develop the outstanding works, not just staying in the acquisition stage.

c) Game industry

Alpha acquired "Philharmonic Tour" already has excellent performance. In 5 years, companies need to create new hand travel products, and the animation and toy industries combined, promoting each other.

d) Film industry

Alpha Film was founded in 2014, the introduction of professionals, professional management of the film business operations. Through cooperation with Hollywood studios cut starting point competition, on the one hand to get Hollywood blockbusters including earnings sharing, distribution rights and related commercialization equity; on the other hand, Alpha learn from the Hollywood's advanced concepts and business model. Alpha should enhance the influence of intellectual property rights.

In the next 5 years, Alpha should have at least 2 films on show, which all have a hundred-million-dollar total box office.

\subsection{Strategy Implementation}

Through the part of the development of the strategic objectives of the Alpha and planning, we have a clear understanding of the Alpha's strategic direction. This chapter will focus on the company's overall strategic objectives, the strategic objectives of each industry, combined with the adjustment planning and management of industrial integration plan proposes measures Alpha strategy over the next five years. Concrete adjustment measures divided into two aspects of management and business development measures to elaborate.

\subsubsection{Organizational Restructuring}

The front part of the strategic objectives and plans have been proposed Alpha mode to adjust the company's management plan, based on a comprehensive portfolio characteristics, set the principle of decentralization, the headquarters function orientation and other factors, the overall organizational structure of the company's conduct partial adjustment. Specific adjustment measures are as follows:

The organization is an organization's overall structure under the influence of corporate governance requirements, management orientation, management and operational characteristics and other factors, the internal organizational resources, build processes, conduct business, the implementation of the basic elements of management. Play management value through organizational change and management to enhance and promote the rapid development of the business. Through organizational change, Alpha should promote the restructuring and development of the company's business. Traction and play a supporting role in organizational change among departments to strengthen the forward-looking business, play pulling direction of the company and promote the company's role in the management of change Financial Management Department, Legal De- 
partment, Human Resources, capital strategies and other functional departments. Meanwhile, the departments have to play the role of business support partner to help businesses improve performance and prevent risks, realized gains.

Emphasis on the development of information technology management functions, Alpha should focus on the development of information technology planning, making sure that information technology plays an active role in efficiency of business and optimal allocation of resources. With the era of interactive entertainment, they will become an important business to support Alpha.

Strengthen the internal coordination and format the internal and external mechanisms for effective interaction. Alpha should gradually expand the industrial chain. Each business unit will strengthen business collaboration, particularly enhanced with new business, and form a clear and effective cooperation.

Establish a strategic connection and address cultural consensus. Alpha should set up a two-stage operation functions, good guidance and support for the business group. Core concept and a clear Alpha sort of corporate culture, values, sort out and clear, making the inner strength to unite the people, to solve the problem of cultural consensus strategy under. Alpha should accelerate organizational change and increase mechanism innovation. 2015 establishment of the Group control mode, with business groups and business units as its core business entities, sinking functional management, fully authorized. While encouraging innovation, mechanism allows the existence of different management methods. And Alpha should strengthen product innovation ability and develop in-house culture of innovation.

\subsubsection{The Adjustment of Acquisition Management Mode}

Alpha entered different industries through the acquisition of animation, games, television, movies and other industries. The acquisition involves a number of different industries, which is too frequent. Actually, the company's resources need to be more focused. Therefore, the acquisition modes should be modified and the company's core competitiveness should be enhanced.

Comprehensive utilization of resources acquired will be animation, games and movies together. Enhance cooperation between different industries, shared resources. The cartoon image acquisition licensed to games and movies. Existing branded content continues to increase innovation, by increasing the level of programming, re-deploy the new movie, to specialize in licensing and brand promotion management, so that the "Pleasant Goat and Big Wolf", "Info programme”, "armor", "Happy Baby”, "Bacon Bear”, "Super Flying Man” and other Alpha IP core can be escalated. Alpha should develop its own brand licensing business and improve the professional level of licensing business. Open all categories licensing market, particularly to increase the authorized share of consumer goods, so that Alpha maximize brand awareness. While focusing authorized partner of choice, service and management, helping them to achieve business growth, the real win-win and sustainable licensing business. 
Alpha should enhance the influence of Jiajia Cartoon channel and release the value of market. Promoting the floor covering work in 2015 focused on 35 cities nationwide, the joint Alpha multi-screen, build quality column, increase the education business and expand the integration of multi-screen business, open up the "Media + programming + advertising", the future will achieve "Jiajia Cartoon + Toys + mutual entertainment" synergy, implement business model upgrade, toys, entertainment and other services through mutual Jiajia Cartoon enlarge. With the Alpha Pictures of international resources and marketing capacity, increase investment and innovation content, further enlarge its own IP's brand value and influence to build movie business model.

\subsubsection{Integration of Research \& Development Resources}

As for research and development ( $\&$ D) resources, the Alpha will use the company's research and development center of acquisitions as the main body. With R \& D management mechanism based on the establishment of the company's overall operation and management mode, the implementation of technological innovation-oriented development strategy, strengthen enterprise and the outside world, each R \& D cooperation between industry, enhance research and development of hard power. Related measures are as follows:

Deeply focus on the use of traditional culture traditional cultural resource development research anime content. Animation as a unique form of artistic expression, its own inherent cultural attributes, will be an excellent animation works more or less carrying the local cultures. Culture is a nation's identity, traditional culture is the collective memory of a nation and a common memory, the nation's culture is unique, each country has its own unique cultural identity. Anime content combined with the R \& D to strengthen the nation's traditional culture, contemporary Chinese animation authors also try to Chinese elements into his works, but only apply the traditional culture of the "shell". "The nation is the world," stand on the world culture, we can see the cultural products with national distinctive features touted by everyone.

1) Increase the use of modern cultural resources

Increase the development and utilization of modern cultural resources, emphasis on modern and contemporary art culture of high parity value of cultural resources, the absorption of open modern culture, in combination with the traditional culture, and rub in constant collision of old and new culture a new spark, provide excellent sources of content development story anime.

2) Improve animation creativity ability

Anime creation is the process of formation of intellectual property is the foundation for all subsequent development. Create more outstanding animation works, copyright trading, derivatives of potential consumers of animation more and more, companies realize greater profits. Although the company already has some creative ability anime, 4 - 5 works each year, but existing anime but the content and influence, the Alpha and excellent domestic anime has some gaps, such as the original power The "Pleasant" series, Hunan macro dream of "Rain- 
bow Cat and Blue Rabbit series." Therefore, the need to strengthen the analysis Alpha market positioning and consumer demand, improve the creative and production anime, rational use of new technology to improve the animation content creation capabilities. Suitable acquisitions, but also make up their own weaknesses creativity way.

\subsubsection{Integration of Human Resources}

Accelerate the introduction of convergence of talent, establish a more diverse incentive. Accelerate the growth of talent to enhance existing, and the introduction of external talent integration, providing a broader stage and development space for the existing team. Encourage diversification while establishing mechanisms to share the fruits of growth, achieve win-win business and employees. Alpha walking in the whole industry chain process, faced by more opportunities and greater challenges, the Group's talent pool required to form echelon corporate mission and vision is to develop a large number of able to make business leaders centennial person.

Attract and develop outstanding creative talent of animation. Human resources is one of the core resources of the animation industry, outstanding innovators, director, screenwriter, animation design, animation industry is a scarce resource, and it is the postulated of creating good animation. Alpha needs to strengthen human resources for investment, improving the business performance evaluation and incentive systems, high-end talent, vision and personal capacity by way of incentive stock options to organize together. Alpha is also needed to improve self-improvement training system, the domestic animation industry is still in a preliminary stage, compared with the excellent animation creation internationally, there is a big gap, inviting international animation business or outstanding animation talent, strengthen Excellent for internal staff training is an important way to cultivate talents, companies can also communicate with the world's leading animation companies, enhance the capacity of employees. This is an important means to attract and retain key employees. In addition, the practice will be reflected in the axiomatic knowledge into policy or operational means to guide in the form of explicit knowledge, but also to achieve just copied, an effective way to promote internal training.

\subsubsection{Resource Integration Sales}

1) Open up the "Content + Media + advertising" spread the whole link

The company enhances the layout in the "Content", "Media" and "advertising" in three areas, improve industrial collaboration capabilities. In content production, the company invested in Beijing Alpha multiscreen Culture Media Co., responsible for TV content production and multi-frequency distribution, the company produced "Where the family" and "the whole family" and family entertainment in Jiajia After the cartoon aired enhance the overall program level, and promote the ratings climbed. The company holding the leading mobile comic platform "magic screen", accelerate the development of cartoon TV Jia 
Jia, clearly create a "China's leading family entertainment channel," the new target, together with the existing Beijing Vientiane entertainment through the company's "watch animation" Mobile end of the video channel, media platform company layout and audiences comprehensive coverage acceleration.

At the same time, the company holding the sand One (Beijing) Culture Media Co., Ltd., the layout of media advertising operator, formed the media matrix Trinity, is expected in the future to create a strong multi-screen media brand, and boosting resources become scarce Austrian flying industry.

\section{2) Authorize the accelerated development of the electricity supplier}

Companies rely on business electricity supplier IP and related derivatives lead, fast layout of the development, has realized cooperation with eight business platform, and to achieve maternal child first category of the whole network, on-line sales to achieve substantial growth, the annual electricity Suppliers tax revenue more than 300 million, an increase of over $400 \%$. The second half of 2014, the company invested 60 million yuan to its own funds to establish a wholly-owned subsidiary "Shanghai Alpha Network Technology Co., Ltd." clearly greater efforts to promote the electric provider business, and expand the market space.

As for the licensing business, the company increased authorized team building, business planning and integration, and the introduction of industry veteran talent. On the license manager truly entered the era of specialization, the new licensing business marketing departments, and by expanding the size of the design teams to enhance the level of creative products, to provide a better brand marketing services for the licenses.

\subsection{Summary}

This chapter analyzes the whole industry strategy, makes some measures that should be taken on Alpha and Alpha's problems in the development process. According to the academic theories, Alpha was analyzed to develop a strategy for its future.

\section{Conclusions}

Alpha company as an A-share market as the "anime first unit," its development strategy research has important significance, because the listed companies in the fierce competition in several industries continue to grow so that the leading position among the industry. This article focuses on the company's strategy of Alpha Research, first elaboratedly chooses the thesis topic research background, significance and research status, then flies to the Austrian company's external environment and related industries competitive environment overview, followed by brief Alpha's profile and history, and analyzes on the Alpha within the industry in their respective industry's competitiveness, and describes the classification of resources Austrian flying company currently owns, on this basis, using SWOT and PEST model research tools within the Alpha external environment and 
overall advantages and disadvantages analysis, interpretation of portfolio positioning, strategic analysis of the company. And based on the analysis, results presented Alpha's strategic objectives, planning and implementation measures.

After a series of analysis of this paper, the conclusions are as follows:

First, through the analysis of the environment inside and outside, the Alpha Company found that Austrian flying company operated in good condition, outlook, multiple industry leading position in the domestic market share, quality and other aspects, but still needed to improve their ability to innovate and strengthen Property Portfolio interoperability, to form a larger overall competitiveness.

Second, the proposed development in line with the company's diversification strategy points to a SWOT analysis based on the results, and the establishment of the company's overall strategic objectives and various industries. Around the strategic objectives are by optimizing their strategic plan to enhance the individual business units.

Third, the strategic objectives and the development of planning for the future development of the company put forward specific company-wide strategy, including organizational restructuring, acquisition management mode adjustment, research and innovation resource integration, integration of human resources, sales integration of resources in five aspects of management adjustment measures in order to achieve a comprehensive upgrade of the company's overall strength of the Austrian flying.

These are the results of this study: Austrian flying company's strategy, hoping to Alpha's senior leadership in the development of the company's long-term strategic planning process plays a role in decision making, in order to help Austrian flying company in long-term development of enterprises Foundation Evergreen.

\section{Acknowledgements}

At the point of finishing this paper, I'd like to express my sincere thanks to all those who have lent me hands in the course of my writing this paper. First of all, I'd like to take this opportunity to show my sincere gratitude to my supervisor, Dr. Zhang Ping, who has given me so much useful advices on my writing, and has tried her best to improve my paper. Secondly, I'd like to express my gratitude to my classmates who offered me references and information on time. Last but not the least, I'd like to thank those leaders, teachers and working staffs. Without their help, it would be much harder for me to finish my study and this paper.

\section{References}

[1] Allee, T.L. and Huth, P.K. (2006) Legitimizing Dispute Settlement: International Legal Rulings as Domestic Political Cover. American Political Science Review, 100, 219-234. https://doi.org/10.1017/S0003055406062125 
[2] Atuahene-Gima, K. (2005) Resolving the Capability-Rigidity Paradox in New Product Innovation. Journal of Marketing, 69, 61-83. https://doi.org/10.1509/jmkg.2005.69.4.61

[3] Belkhyr, S. (2012) Disney Animation: Global Diffusion and Local Appropriation of Culture. International Journal of Human Sciences, 9, 704-714.

[4] Liao, W. (2009) Research on the Growth of China's Original Animation. Zhongnan University, Changsha.

[5] Thomas, R.R., Thomas, D.A., Ely, R.J., et al. (1995) Harvard Business Review on Managing Diversity. Harvard Business Review, 76, 86-92.

[6] Liu, C. (2011) Research on Animation Brand Value Evaluation and Management System-Based on Evolutionary Economics. Zhongnan University, Changsha.

[7] Gandia, R. (2013) The Digital Revolution and Convergence in the Videogame and Animation Industries: Effects on the Strategic Organization of the Innovation Process. International Journal of Arts Management, 15, 32-33.

[8] Yang, J. (2014) Research on China's Animation Industry Competence Based on Diamond Theory. Dalian Ocean University, Dalian.

[9] Koike, D.O.A. (2010) Working Conditions of Animators: The Real Face of the Japanese Animation Industry. Creative Industries Journal, 3, 261-271.

[10] Plambeck, E.L. and Taylor, T.A. (2005) Sell the Plant? The Impact of Contract Manufacturing on Innovation, Capacity, and Profitability. Management Science, 51, 133-150. https://doi.org/10.1287/mnsc.1040.0212

[11] Sun, L. (2011) Research on China's Own Brand of Toy Design. Tianjin University of Science and Technology, Tianjin.

[12] Gandia, R. (2013) The Digital Revolution and Convergence in the Videogame and Animation Industries: Effects on the Strategic Organization of the Innovation Process. International Journal of Arts Management, 15, 32-44.

[13] Zhang, J. and Li, F. (2014) Integrational Expansion and Reconstruction of Absorptive Capacity of Enterprises. Science and Technology Progress and Policy, No. 17, 37-42.

[14] Zhang, Y., Feng, S., Zhang, Y., et al. (2014) Evaluation of Internet Finance and China's Traditional Banking. South China Finance, No. 6, 27-30.

[15] Zhao, Y. and Zhang, W. (2012) The Challenges and Countermeasures of Transition from Manufacturer to Service Provider in China: Based on Inertia Theory. Science of Science and Management, 33, 129-135. 